\title{
ANALISA LOGAM TIMBAL (Pb) PADA RAMBUT MEKANIK DIDAERAH KAMPUNG LALANG SECARA SPEKTROFOTOMETER SERAPAN ATOM
}

\author{
Dyna Grace Romatua Aruan', Nurkholis Azhar ${ }^{2}$ \\ ${ }^{12}$ Fakultas Pendidikan Vokasi, Universitas Sari Mutiara Indonesia \\ Email: dynaaruan1245@gmail.com,nurkholisazhar20@gmail.com
}

\begin{abstract}
ABSTRAK
Timbal $(\mathrm{Pb})$ merupakan salah satu jenis logam berat berbahaya dan toksik bagi tubuh manusia. Mekanik merupakan salah satu profesi dibidang mesin kendaraan bermotor, dimana kemungkinan terpapar partikel $\mathrm{Pb}$ akibat polusi atau emisi gas kendaraan bermotor dengan kadar jauh lebih tinggi dibanding dengan masyarakat lainnya sangat nyata. Terakumulasinya $\mathrm{Pb}$ pada penelitian ini memberi gambaran bahwa lama bekerja sangat mempengaruhi kadar logam $\mathrm{Pb}$ dalam rambut pekerja. Penelitian ini bertujuan untuk menganalisis kadar timbal pada rambut mekanik di daerah Kampung Lalang. Penelitian ini dilaksankan di UPT Laboratorium Kesehatan Daerah Provinsi Sumatera Utara dengan menggunakan alat Spektrofotometer Serapan Atom. Dari 6 keseluruhan populasi, penelitian mengambil sampel Rambut dari 6 (enam) orang Mekanik. Kadar $\mathrm{Pb}$ pada 6 (enam) sampel Rambut mekanik di Daerah Kampung Lalang Secara Spektrofotometer Serapan Atom Tahun 2021, Dengan varabel lama kerja > 10 th (R5) $57.25 \mathrm{mg} / \mathrm{kg}$ termasuk tingkat pencemaran tinggi $>25 \mathrm{ppm}$,sedangkan sampel dengan lama kerja $5-10$ th $2.115 \mathrm{mg} / \mathrm{kg}$ dinyatakan mengandung timbal dengan kategori pencemaran yang rendah $<10$ ppm, sedangkan 4 Sampel dinyatakan tidak mengandung $\mathrm{Pb}$ yaitu pada kode sampel Rambut R1,R2,R3,dan R6.Dan disarankan kepada peneliti selanjutnya agar melakukan penelitian dengan mengambil sampel lain seperti darah untuk mendapat hasil yang lebih akurat.
\end{abstract}

Kata Kunci : rambut, timbal (Pb), mekanik, spektrofotometer serapan atom

\section{ABSTRACT}

Lead $(\mathrm{Pb})$ is a type of heavy metal that is dangerous and toxic to the human body. Mechanics is one of the professions in the field of motorized vehicle engines, where the possibility of exposure to $\mathrm{Pb}$ particles due to pollution or motor vehicle gas emissions with levels much higher than other communities is very real. The accumulation of $\mathrm{Pb}$ in this study illustrates that the length of work greatly affects the levels of $\mathrm{Pb}$ in the hair of workers. This study aimed to analyze the lead content in mechanical hair in the Kampung Lalang area. This research was carried out at the UPT Regional Health Laboratory of North Sumatra Province using an Atomic Absorption Spectrophotometer. From 6 total populations, the study took hair samples from 6 (six) mechanics. Pb levels in 6 (six) samples of mechanical hair in the Kampung Lalang area by Atomic Absorption Spectrophotometer in 2021, with a variable duration of work > 10 years (R5) $57.25 \mathrm{mg} / \mathrm{kg}$ including high pollution levels $>25 \mathrm{ppm}$, while samples with a working duration of 5- 10 years $2.115 \mathrm{mg} / \mathrm{kg}$ was declared to contain lead with a low pollution category $<10 \mathrm{ppm}$, while 4 samples were declared not to contain $\mathrm{Pb}$, namely the Hair sample code R1, R2, R3, and R6. And it is recommended to further researchers to conduct research by taking samples such as hair or blood for more accurate results

Keyword: hair, lead (Pb), mechanical, atomic absorption spectrophotometer

Universitas Sari Mutiara Indonesia

DOI: https://doi.org/10.51544/jalm.v6i2.2342 
Dyna Grace Romatua Aruan et. All | Analisa Logam Timbal (Pb) pada Rambut Mekanik di Daerah Kampung Lalang secara Spektrofotometer Serapan Atom

\section{PENDAHULUAN}

Udara bersih adalah udara yang cukup akan kebutuhan oksigen (02) yang dibutuhkan makhluk hidup untuk proses fisiologis normal. Di daerah perkotaan yang ramai, gas pencemar berasal dari asap kendaraan, gas buangan pabrik, pembangkit tenaga listrik, asap rokok dan sebagainya yang erat hubungannya dengan aktivitas kehidupan manusia (Darmono, 2009).

Pertambahan jumlah kendaraan bermotor sekarang yang sangat pesat memberikan dampak negatif bagi yang bekerja di pinggir jalan raya. Kendaraan bermotor merupakan penyumbang utama dari seluruh emisi racun di udara. Satu diantaranya emisi racun di udara adalah logam timbal. Polusi udara ini dapat menyebabkan penyakit jika terakumulasi terlalu lama dalam darah manusia (Ardyanto 2005)

Mekanik merupakan salah satu profesi dibidang mesin kendaraan bermotor, dimana kemungkinan terpapar partikel $\mathrm{Pb}$ akibat polusi atau emisi gas kendaraan bermotor dengan kadar jauh lebih tinggi disbanding dengan masyarakat lainnya sangat nyata. Oleh karena itu, paparan $\mathrm{Pb}$ akan lebih cepat, apabila disertaiin dengan durasi paparan yang panjang. Menurut penelitian sebelumnya yang dilakukan oleh Wahyu (2015) mengantakan bahwa kadar timbal $\mathrm{Pb}$ rambut Polantas dikota Bengkalis sebesar $2.56 \mathrm{ppm}$ dan termasuk dalam kategori pencemaran rendah menurut WHO tahun 1995.

Pada Rambut gugus sulfhidril dan disulfida dalam rambut mampu mengikat unsur runut yang masuk ke dalam tubuh dan terikat di dalam rambut. Senyawa sulfida mudah terikat oleh unsur runut, maka bila unsur runut masuk ke dalam tubuh, unsur runut tersebut akan terikat oleh senyawa sulfida dalam rambut (Pettrucci, 1982).

Universitas Sari Mutiara Indonesia

DOI: https://doi.org/10.51544/jalm.v6i2.2342
Unsur timbal yang terabsorpsi baik langsung lewat udara atau maupun tidak langsung melalui makanan yang terpapar timbal (ikan dalam kolam) diangkut oleh darah ke seluruh organ tubuh, dimana terabsorpsi dalam tubuh dapat terikat dan merusak jaringan tubuh atau diekresikan melalui urin, feses, keringat, rambut dan kuku. Timbal dalam darah vaitu sebanyak 95\% terikat olen eritrosit dan disebarkan ke seluruh jaringan tubuh dapat terdeposit pada jaringan lunak (sumsum tulang, sistem saraf, ginjal, dan hati) dan jaringan keras (tulang, gigi, kuku dan rambut). Unsur timbal dalam jaringan lunak bersifat toksik terhadap jaringan itu sendiri (Sudarmaji et al., 2006).

Sekitar $90 \%$ timbal yang terserap oleh darah berikatan dengan sel-sel darah merah (Palar, 2008). Menurut WHO batasan kadar timbal pada darah yaitu di bawah $10 \mathrm{ug} / \mathrm{dL}$ (ppm) dikategorikan rendah, dan di atas 25 ug/dL dikategorikan tinggi (Marianti, 2013). Timbal yang diabsorpsi oleh tubuh akan mengikat gugus aktif dari enzim ALAD (Amino Levulinic Acid Dehidrase), dimana enzim ini berfungsi pada sintesis sel darah merah. Adanya senyawa timbal akan mengganggu kerja enzim ini sehingga sintesa sel darah merah menjadi terganggu (Palar, 2008).

Beberapa gejala yang timbul akibat terpapar timbal secara kronis termasuk diantaranya adalah kehilangan libido, infertilitas laki-laki, gangguan menstruasi, serta aborsi spontan pada wanita. Pada lakilaki telah terbukti adanya perubahan dalam spermatogenesis. Hal ini juga senada dengan hasil penelitian dari Harianto Ludirdja tahun 1994 yang menyimpulkan bahwa pada polisi lalu lintas mempunyai jumlah spermatozoa (19,5 juta spermatozoa/ml) lebih rendah dari standar normal (2 $20 \mathrm{juta} / \mathrm{ml}$ ), gerakan spermatozoa $(44,5 \%)$ lebih rendah dari standar normal (250\%) dan bentuk spermatozoa normal $(39,3 \%)$ mempunyai nilai yang lebih rendah dari standar normal (2 
$50 \%$ ) dan timbal yang melewati plasenta pada wanita hamil yang terpapar timbal selama kehamilan dapat menyebabkan kematian akibat terpapar dan toksisitas (Riyadina, 1997).

Keracunan timbal dapat menyebabkan efek akut dan kronis. Keracunan akut yaitu akibat pemaparan yang terjadi dalam waktu yang relatif singkat (dapat terjadi dalam waktu 2-3 jam), dengan kadar yang relatif besar. Keracunan akut yang disebabkan oleh timbal biasanya terjadi karena kecelakaan misalnya, peledakan atau kebocoran yang tiba-tiba dari uap logam timbal, kerusakan sistem ventilasi di dalam ruangan. Keracunan akut ditandai oleh rasa terbakar pada mulut, terjadinya perangsangan dalam gastrointestinal, dan diikuti dengan diare. Keracunan kronis terjadi karena absorpsi timbal dalam jumlah kecil, tetapi dalam jangka waktu yang lama dan terakumulasi dalam tubuh. Gejala keracunan kronis ditandai oleh rasa mual, anemia, sakit di sekitar perut, dan dapat menyebabkan kelumpuhan. Organ-organ tubuh yang menjadi sasaran dari keracunan timbal adalah sistem peredaran darah, sistem saraf, sistem urinaria, sistem reproduksi, sistem endokrin, dan jantung (Palar, 2008).

Studi toksisitas timbal menunjukkan bahwa kandungan timbal dalam darah sebanyak $100 \mu \mathrm{g} / \mathrm{L}$ dianggap sebagai tingkat aktif (level action) berdampak pada gangguan perkembangan dan penyimpangan perilaku. Sedangkan kandungan timbal $450 \mathrm{ug} / \mathrm{L}$ membutuhkan perawatan segera dalam waktu 48 jam. Kandungan timbal lebih dari 700 $\mu \mathrm{g} / \mathrm{L}$ menyebabkan kondisi gawat secara medis (medical emergency). Kandungan timbal di atas $1.200 \mathrm{ug} / \mathrm{L}$ bersifat sangat toksik dan dapat menimbulkan kematian. Pada anak, kadar timbal 68 ug/L. danat menyebabkan anak makin agresif, kurang konsentrasi, bahkan menyebabkan kanker. Pada anak, kadar keracunan timbal yang tinggi dapat menyebabkan anemia, kerusakan otak, hati, ginjal, saraf dan pencernaan, koma, kejang-kejang atau epilepsi, serta dapat menyebabkan kematian (Naria, 2005).

Berdasarkan penelitian yang telah dilakukan dengan bioindikator rambut bahwa dengan uji signifikan dan regresi linier terdapat korelasi positif antara lama bekerja dengan kandungan timbal dalam rambut pekerja, khususnya pekerja SPBU (Subagiada, 2011).

Dari latar belakang di atas maka peneliti tertarik untuk melakukan penelitian yang bertujuan untuk menganalisis kadar timbal pada rambut mekanik di daerah Kampung Lalang.

\section{METODE PENELITIAN}

Jenis penelitian ini bersifat deskriptif dengan menggunakan metode Spektrofotometer Serapan Atom (SSA) yang bertujuan untuk mengetahui kadar timbal $\mathrm{Pb})$ pada rambut mekanik di daerah Kampung Lalang, Medan, Tahun 2021. Lokasi pengambilan sampel dilakukan di sekitaran Kampung Lalang, Medan dan dilanjutkan dengan uji laboratorium di UPT balai laboratorium kesehatan daerah provinsi sumatera utara jalan Williem Iskandar Pasar V Barat 1 No, 4 Medan. Penelitian dilakukan pada April-Agustus 2021. Populasi dalam penelitian ini adalah mekanik yang berada di daerah Kampung Lalang sebanyak 20 orang, dan sampel dalam penelitian ini diambil secara acak (random sampling) sebanyak 6 orang mekanik yang berada di daerah Kampung Lalang.

\section{Universitas Sari Mutiara Indonesia}




\section{Peralatan yang Digunakan}

\begin{tabular}{|llll|}
\hline No & Nama Alat & Ukuran & Merek \\
\hline 1 & Beaker glass & $50 \mathrm{ml}$ & Pyrex \\
2 & Labu ukur & $50 \mathrm{ml}$ & Pyrex \\
3 & Batang pengaduk & - & - \\
4 & Erlemmeter & $50 \mathrm{ml}$ & Pyrex \\
5 & Pipet volume & $10 \mathrm{ml}$ & Pyrex \\
6 & Kaca arloji & - & - \\
7 & Waterbath & - & Memmert \\
8 & Neraca analitik & - & AND GR-200 \\
9 & Hot plate & - & Maspion \\
10 & Spektrofotometer serapan & - & Varian \\
& atom & - & - \\
11 & Kantong poliselin & - & Memmert \\
13 & Oven & - & - \\
\hline
\end{tabular}

\section{Bahan yang Digunakan}

\begin{tabular}{|lll|}
\hline No & Nama Reagensia & Rumus Kimia Reagensia \\
\hline 1 & Asam Nitrat Pekat $65 \%$ & $\mathrm{HNO}_{3}(\mathrm{p})$ \\
2 & Kalium Kromat $1 \%$ & $\mathrm{~K}_{2} \mathrm{CrO}_{4}$ \\
3 & Kalium Iodida $1 \%$ & $\mathrm{KI}$ \\
4 & Asam Klorida & $\mathrm{HCI}(\mathrm{P})$ \\
5 & Aseton & $\mathrm{C}_{3} \mathrm{H}_{6} \mathrm{O}(\mathrm{P})$ \\
6 & Detergen & $\mathrm{NaC}_{12} \mathrm{H}_{25} \mathrm{SO}_{4}$ \\
7 & Aquadest & $\mathrm{H}_{2} \mathrm{O}$ \\
\hline
\end{tabular}

\section{Proses Persiapan Dektruksi Sampel Rambut}

1. Untuk dektruksi sampel, maka timbang rambut tersebut sebanyak 0,5 gram secara akurat kedalam beaker glass.

2. Kemudian di tambah $\pm 15 \mathrm{ml} \mathrm{HCI}$ dan $5 \mathrm{ml} \mathrm{HNO}_{3}$ dan di tutup dengan kaca arloji yang sesuai.

3. Larutan di panaskan hingga mendidih \pm 30 menit diatas lemari asam

4. Kemudian penutup kaca arloji dibuka dan larutan diuapkan di atas waterbath.

5. Kemudian tambahkan lagi $12,5 \mathrm{ml} \mathrm{HNO}_{3}$
6. Lalu larutan dipanaskan sampai larut semua dan kembali didinginkan di atas Desikator.

7. Bila masih terdapat endapan, sampel disaring dengan kertas Whatmann lalu filtratnya diambil.

8. Masukkan filtrate tersebut ke dalam labu ukur $50 \mathrm{~mL}$, lalu tambahkan aquadest sampai tanda batas.

9. Sampel siap untuk dianalisa. 


\section{Rumus perhitungan}

Konsentrasi sampel $\mathrm{Pb}(\boldsymbol{m g} / \mathbf{k g})=\frac{\boldsymbol{A} X \boldsymbol{B}}{\boldsymbol{g} \text { Sampel }}$

Dimana :

A: Konsentrasi Logam Yang Diserap (mg/L)

B: Volume Larutan Yang Diserap (ml)

g/Sampel: Gram Sampel yang ditimbang (gr)

\section{HASIL DAN PEMBAHASAN}

Dari hasil penelitian yang dilakukan pada 6 (enam) sampel Rambut yang diperiksa di UPT Laboratorium Kesehatan Daerah Provinsi Sumatera Utara pada 14-15 Juni 2021 diperoleh hasil sebagai berikut.

Tabel 1.

Data deret standart

\begin{tabular}{|c|c|}
\hline Konsentrasi & Absorbansi \\
\hline 0,034 & $-0,002$ \\
\hline 0,503 & 0,0298 \\
\hline 1,01 & 0,0591 \\
\hline 1,977 & 0,1114 \\
\hline 4,011 & 0,2042 \\
\hline
\end{tabular}

Tabel 2.

Data Hasil Uji Kuantitatif Pemeriksaan Kadar Pb pada Rambut Mekanik dengan Spektrofotometer Serapan Atom

\begin{tabular}{|c|c|c|c|c|c|c|}
\hline No & Kode & Usia & $\begin{array}{c}\text { Lama } \\
\text { Kerja }\end{array}$ & Satuan & $\begin{array}{c}\text { Hasil Analisa } \\
\text { Timbal }(\mathbf{P b})\end{array}$ & $\begin{array}{c}\text { Tingkat Pencemaran Pb } \\
\text { Berdasarkan WHO Tahun } \\
\mathbf{1 9 9 5}\end{array}$ \\
\hline 1 & $\mathrm{R} 1$ & 28 & $<3$ tahun & $\mathrm{mg} / \mathrm{kg}$ & $<0,0170$ & Tidak Terdapat $\mathrm{Pb}$ \\
\hline 2 & $\mathrm{R} 2$ & 25 & $<3$ tahun & $\mathrm{mg} / \mathrm{kg}$ & $<0.0170$ & Tidak Terdapat $\mathrm{Pb}$ \\
\hline 3 & $\mathrm{R} 3$ & 29 & $3-5$ tahun & $\mathrm{mg} / \mathrm{kg}$ & $<0.0170$ & Tidak Terdapat $\mathrm{Pb}$ \\
\hline 4 & $\mathrm{R} 4$ & 35 & $5-10$ tahun & $\mathrm{mg} / \mathrm{kg}$ & 2.115 & \begin{tabular}{c} 
Memasuki tingkat \\
pencemaran rendah $<10 \mathrm{ppm}$ \\
Memasuki tingkat \\
\hline 5
\end{tabular} \\
\hline 6 & $\mathrm{R} 5$ & 34 & $>10$ tahun & $\mathrm{mg} / \mathrm{kg}$ & 57.25 & $\begin{array}{c}\text { Pencemaran tinggi }>25 \mathrm{ppm} \\
\text { Tidak Terdapat } \mathrm{Pb}\end{array}$ \\
\hline
\end{tabular}

Dari Tabel 4.2 Data Hasil Penelitian, diperoleh hasil yang menunjukkan kadar $\mathrm{Pb}$ pada 6 (enam) sampel Rambut mekanik di Daerah Kampung Lalang Secara Spektrofotometer Serapan Atom Tahun 2021,

Universitas Sari Mutiara Indonesia

DOI: https://doi.org/10.51544/jalm.v6i2.2342 dengan varabel lama kerja > 10 th (R5) 57.25 $\mathrm{mg} / \mathrm{kg}$ termasuk tingkat pencemaran tinggi $>25$ ppm, sedangkan sampel dengan lama kerja $5-10$ th (R4) $2.115 \mathrm{mg} / \mathrm{kg}$ dinyatakan mengandung timbal dengan kategori 
pencemaran yang rendah $<10$ ppm, sedangkan 4 Sampel dinyatakan tidak mengandung $\mathrm{Pb}$ yaitu pada kode sampel Rambut R1,R2,R3,dan R6.

Adanya kadar $\mathrm{Pb}$ dalam rambut tersebut dapat masuk ke dalam tubuh melalui jalur pernafasan dan jalur pencernaan. Timbal $(\mathrm{Pb})$ yang masuk ke dalam tubuh dapat terakumulasi dan bersifat toksik dengan menimbulkan kerusakan organ dan sistem di dalam tubuh. Faktor yang menyebabkan hasil kadar $\mathrm{Pb}$ pada peneliti bernilai positif yaitu dari tingkat lama perkerjaan, terjadinya perbedaan dan kesamaan nilai konsentrasi di antara beberapa sampel di atas tidak hanya di pengaruhi oleh rentang masa bekerja saja namun pola hidup, keadaan lingkungan dan kebiasaan memakai alat pelindung diri (APD) yang berbeda beda. Semakin lama bekerja pada tempat yang terpapar $\mathrm{Pb}$ maka potensi terakumulasi kadar $\mathrm{Pb}$ dalam rambut, semakin besar.

Penelitian ini memberi gambaran bahwa lama bekerja sangat mempengaruhi kadar logam $\mathrm{Pb}$ dalam rambut pekerja dan lingkungan yang berpotensi terpolusi $\mathrm{Pb}$ kemungkinan yang sangat besar untuk mengabsorpsi timbal ke dalam tubuh pekerja, Ion logam $\mathrm{Pb}$ berbentuk partikulat yang terdapat di udara hasil pembakaran kendaraan bermotor perlahan akan masuk kedalam jaringan rambut dan diikat oleh gugus sulfihidrin yang berbeda pada rambut sehingga Logam $\mathrm{Pb}$ akan mengendap didalam jaringan rambut dan beredar masuk ke dalam darah pada batas waktu tertentu. Gugusangugusan sulfhidril (-SH) dan sulfide sistin (S-S-) dalam rambut mampu mengikat logam berat yang masuk ke dalam tubuh dan terikat di dalam rambut. Mengingat bahwa senyawa sulfide mudah terikat oleh logam berat, maka bila logam berat masuk kedalam tubuh, logam-logam tersebut akan terikat oleh senyawa sulfide dalam rambut.

\section{Universitas Sari Mutiara Indonesia}

DOI: https://doi.org/10.51544/jalm.v6i2.2342
Adapun bahaya logam berat $\mathrm{Pb}$ jika masuk ke dalam tubuh dapat mengganggu kesehatan. Senyawa timbalnya masuk ke dalam tubuh dapat mempengaruhi metabolisme tubuh, efek toksik logam dapat menghambat pembentukan $\mathrm{Hb}$, kerusakan pada sistem syaraf, sistem urinaria, sistem reproduksi, sistem jantung, dan ginjal.

\section{SIMPULAN}

Dari hasil penelitian yang dilakukan di UPT Laboratorium Kesehatan Daerah Provinsi Sumatera Utara menunjukkan hasil bahwa kadar $\mathrm{Pb}$ (Timbal) pada rambut mekanik yang berada di Daerah Kampung Lalang Medan tahun 2021 diambil kesimpulan yaitu berdasarkan tingkat pencemaran $\mathrm{Pb}$ pada manusia WHO Tahun 1995 tentang kadar timbal pada tubuh manusia, diperoleh hasil tertinggi pada sampel ke R5 yaitu $57.25 \mathrm{mg} / \mathrm{kg}$ termasuk tingkat pencemaran tinggi (>25 ppm) dan terendah terdapat pada sampel R4 yaitu 2.115 $\mathrm{mg} / \mathrm{kg}$ termasuk tingkat pencemaran rendah $(<10 \mathrm{ppm})$ dan selebihnya tidak terdapat $\mathrm{Pb}$ pada sampel. Rekomendasi bagi peneliti lain agar melanjutkan penelitian ini dengan memeriksa specimen tubuh yang lain seperti dari kuku,darah dan urine.

\section{UCAPAN TERIMAKASIH}

Pada kesempatan ini penulis mengucapkan terimakasih yang sebesarbesarnya kedua orangtua, kakak dan adek tercinta yang selalu memberi semangat dan dorongan baik secara moral, doa, dan material dalam melaksanakan penelitian ini. Saya ucapkan terimakasih juga kepada seluruh dosen dan staff pengajar Program Studi Teknologi Laboratorium Medis yang telah banyak memberi ilmu dan mendidik peneliti menjalani pendidikan di Universitas Sari Mutiara Indonesia. Dan terimakasih juga 
kepada teman-teman dan pihak-pihak yang telah membantu dalam melaksanakan penelitian ini.

\section{DAFTAR PUSTAKA}

Ardyanto, D. Deteksi Pencemaran Timah Hitam $(\mathrm{Pb})$ dalam Darah Masyarakat yang Terpajan Timbal (Plumbum). Jurnal Kesehatan Lingkungan. Vol 2(1), 67-76 (2005)

Arianto, M \& Ritonga, A.H.Analisa Kadar Pb Pada Rambut Tukang Becak Sekitaran Jalan Kapten Muslim Medan.Jurnal Analis Laboratorium Medik. Vol 4(1), 8-10 (2019)

Aruan, Dyna Grace Romatua \& Manurung, Sulistina. Analisa Kadar Logam Berat (Pb) Pada Kuku Tukang Tambal Ban Disepanjang Jalan Kapten Muslim secara Spektrofotometer Serapan Atom. Jurnal Analis Laboratorium Medik. Vol 6(1), 42-48 (2021)

Darmono. Lingkungan Hidup dan Pencemaran. Jakarta: Universitas Indonesia Press. (2009)

Handayani, C. \& Zulhidayati, R. Validasi metode analisa kadar timbal $(\mathrm{Pb})$ dalam rambut karyawan SPBU di Indarung. Chempublish Journal. 2 (1), 54-61. (2017)

Palar, H. Pencemaran dan Toksikologi Logam Berat. Jakarta: Rineka Cipta. (1994)

Palar, H. Pencemaran dan Toksikologi Logam Berat. Jakarta: Rineka Cipta. (2004)

Palar, H. Pencemaran dan Toksikologi Logam Berat. Jakarta: Rineka Cipta Grafindo. (2008)

Petrucci, RH. General Chemistry. McMillan Publ, Co, Inc, New York. (1982)

Riyadina, Woro. Pengaruh Pencemaran Pb (Plumbum) Terhadap Kesehatan"

Universitas Sari Mutiara Indonesia

DOI: https://doi.org/10.51544/jalm.v6i2.2342
Badan Penelitian dan Pengembangan. Kesehatan Depkes RI. (1997)

Situmorang, Ing Mayfa $\mathrm{Br} \&$ Simatupang, D.F. Alisis Logam Berat pada Sayuran yang Ditanami di Pinggi Jalan Bekasi Utara. Jurnal Analis Laboratorium Medik. Vol 6(1), 19-22. (2021)

Subagiada, Kadek. Penentuan Kadar Timbal $(\mathrm{Pb})$ dengan Bioindikator Rambut pada Pekerja SPBU Di kota Samarinda. Skripsi. Jurusan Fisika FMIPA, Universitas Mulawarman. (2011)

Sudarmaji, J. Mukono, Corie I.P. Toksikologi Logam Berat B3 dan dampaknya Terhadap Kesehatan. Jurnal Kesehatan Lingkungan. Vol.2(2). (2006) 